\title{
FEMINISMO NA MÚSICA: UMA ANÁLISE DO \\ VIDEOCLIPE “RUN THE WORLD (GIRLS)", DE BEYONCÉ
}

\author{
FEMINISM IN MUSIC: AN ANALYSIS OF THE \\ MUSICAL VIDEO "RUN THE WORLD (GIRLS)" BY BEYONCÉ
}

\begin{abstract}
Resumo
Este artigo discute a presença de signos visuais que remetem ao feminismo, no videoclipe "Run The World (Girls)", da cantora Beyoncé. Para tanto, discute-se a história da mulher, a imagem como forma de linguagem, o surgimento do videoclipe e a carreira de Beyoncé. Os métodos de pesquisa utilizados neste estudo são documental e bibliográfico, e a observação e análise de um documentário da cantora, bem como de um videoclipe que é objeto deste estudo. Para discorrer sobre a história da mulher, utiizase Alves e Pitanguy (1985), Robles (2006) e Sarti (2004), para falar sobre os tipos de feminismo, Heywood (2010), Nye (1998), Nicholson (2010) e Garcia e Miranda (2012). Com o intuito de discutir a imagem como forma de linguagem, utiliza-se Dondis (1997), Aumont (1993) e Deleuze (1983). A análise é baseada na semiótica de Joly (1996) e Santaella (1983), com auxílio de Chevalier (1999), Mondro (2008) e Farina (2006). Através da análise de imagem das figuras do videoclipe foi possível identificar signos utilizados por Beyoncé para discutir feminismo com o público.
\end{abstract}

Palavras-chave: Feminismo. Imagem. Beyoncé. Análise semiótica. Videoclipe.

\begin{abstract}
This article discusses the presence of visual cues that refer to feminism in the music video "Run The World (Girls)", by singer Beyoncé. For this, women's history is discussed, the image as a form of language, the emergence of the musical video and the career of Beyoncé. The research methods used in this study are documentary and bibliographical, and the observation and analysis of the documentary "Beyoncé: Life is but a Dream" and the video clip that is the object of study. Robles (2006) and Sarti (2004), for the types of feminism, Heywood (2010), Nye (1998), Nicholson (2010) and Garcia and Miranda (2012) are some of the theoretical basis of the study. In order to discuss the image as a language, Dondis (1997), Aumont (1993) and Deleuze (1983) are used. The analysis is based on the semiotics of Joly (1996) and Santaella (1983) with the help of Chevalier (1999), Mondro (2008) and Farina (2006). Through the image analysis of the video clips, it was possible to identify signs used by Beyoncé to discuss feminism with the audience.
\end{abstract}

Keywords: Feminism. Image. Beyonce. semiotic analysis. Video clip.

Denise Castilhos de Araujo

Universidade Feevale

E-mail: denisecastilhos@gmail.com

Bianca Lopes

Universidade Feevale

E-mail: bibi.nh@gmail.com 


\section{Introdução}

Aigualdade de gêneros tem sido um tema explorado pela mídia e de interesse de muitas mulheres. Uma das causas desse fenômeno pode ser o fato de que algumas celebridades femininas têm apresentado/discutido este tema, entre elas, a cantora americana Beyoncé. No ano de 2011 a cantora lançou um videoclipe para a música "Run The World (Girls)", que narra o combate entre o avanço feminino para obtenção de igualdade e o consequente recuo masculino.

Por conta de relevância do feminismo no contexto atual e da popularidade de Beyoncé, neste artigo refletese acerca de algumas imagens do videoclipe, discutindo a presença de elementos feministas nesse material. $\mathrm{O}$ videoclipe representa uma manifestação textual da cultura jovem, por isso sua importância como um texto midiático capaz de perpetuar questões sociais como o feminismo. A cantora Beyoncé, com 19 anos de carreira na música, simboliza um processo midiático que envolve o alcance mundial de uma artista. Este artigo discute a opressão contra a mulher ao longo da história mundial e brasileira, além de explicar o surgimento do feminismo em diversos momentos da história, o liberal, o socialista e o radical.

Para discutir o feminismo, Beyoncé utilizou a linguagem visual, e, por isso, define-se imagem, enfatizando que se trata de uma linguagem muito eficiente, bem como sua relação com o espectador e as formas com que ela é recebida.

Outro tema discutido é a trajetória de Beyoncé na música, suas conquistas e sua identificação como feminista. Por fim, é realizada a análise semiótica de três imagens do videoclipe "Run The World (Girls)", selecionadas observando-se sua importância na narrativa do videoclipe, já que representam início, desenvolvimento e final de um texto midiático. A análise é feita com o intuito de identificar elementos do feminismo em relevantes imagens, que são explorados pela cantora.

\section{O feminismo}

Heywood (2010) vê o feminismo como um termo político e ideológico que, através de um movimento, fortalece o papel da mulher na sociedade mundial e combate a desigualdade. Durante anos "a mulher tem sido uma parte silenciosa da memória social, ausente dos manuais escolares e dos registros históricos" (NYE, 1998, p. 10). Tida como o sexo frágil e criada a partir de um pedaço do homem, a mulher foi apagada e desvalorizada da história. Tal discriminação, porém, revela a dimensão da sua resistência ao longo dos séculos.

Alguns teóricos acreditam que os primeiros registros de desigualdade no mundo ocidental foram encontrados na Grécia Antiga, onde as mulheres podiam trabalhar, mas tinham outras limitações, ou seja, o trabalho não era negado à mulher, pois "produzia tudo aquilo que era diretamente ligado à subsistência do homem: fiação, tecelagem, alimentação. Exercia, também, trabalhos pesados como a extração de minerais e o trabalho agrícola" (ALVES E PITANGUY, 1985, p. 11-12). Nessa época, as atividades feitas para o intelecto, como política, artes e filosofia, eram privilégio masculino, a mulher era "excluída do mundo do pensamento, do conhecimento, tão valorizado pela civilização grega" (Ibidem, p. 12).

Na Idade Média, a exclusão do trabalho feito fora de casa e dos estudos, culminou no estereótipo de "mulher frágil e indolente, entretida em bordados e bandolins, à espera de seu cavaleiro andante" (ibidem, p. 19).

Assim, a falta de protagonismo da mulher nas atividades políticas, econômicas e intelectuais culminaram na primeira onda de protestos ao redor do mundo. Diante dessas situações, iniciava o movimento sufragista universal no Século XIX, que se destacou na França durante uma revolução que esquecia as mulheres na luta libertária.

Esse século ficaria marcado pela luta do sufrágio feminino, que, segundo Alves e Pitanguy (1985) durou sete décadas nos Estados Unidos e na Inglaterra. No Brasil, a luta durou 40 anos, atingindo seu resultado em 1932, quando Getúlio Vargas decretou o direito ao voto feminino.

Sarti (2004) afirma que a história do feminismo brasileiro se destacou a partir da década de 1960, dado o contexto político em que o país estava inserido, ou seja, através da resistência à ditadura instituída em 1964 pelos militares. Foi nos anos 1970 que entraram em cena os movimentos de mulheres, que se reuniam em organizações de bairros para encaminhar ao Estado suas demandas de infraestrutura urbana como água, luz e esgoto, por exemplo.

$\mathrm{O}$ crescimento de organizações não governamentais e da ideologia feminista oportunizou mudanças na Constituição Federal, como a extinção da tutela masculina na sociedade conjugal em 1988. 
Ocorreu, também, a criação de leis para dar visibilidade à violência doméstica, tendo delegacias especializadas para receberem a mulher denunciante, segundo Sarti (2004).

De acordo com Nye (1998), o feminismo pode ser classificado em liberal, socialista e radical. O feminismo liberal é ligado ao conceito de liberalismo difundido no século XIX, quando a Europa passou a focar sua economia em indústrias e a expansão do mercado (NYE, 1998).

Considerado a primeira onda feminista, o feminismo liberal defendia que "mulheres deveriam ser dotadas de todos os privilégios políticos, inclusive o voto e o direito de concorrer a cargos públicos. Devia, também, lhes ser facultada a escolha de uma profissão em vez de casar" (ibidem, p. 27-28).

Heywood (2010) pontua as fragilidades do liberalismo, pois a emancipação feminina, através do trabalho e do voto, eram aproveitados principalmente por mulheres brancas, de classe média e instruídas. Esse feminismo criou força na segunda metade do século $\mathrm{XX}$, após mulheres trabalhadoras procurarem uma identificação maior com uma teoria que as integrasse, já que no liberalismo "os interesses e privilégios de classe acabavam prevalecendo, independente do feminismo ficar na moda" (NYE, 1998, p. 48).

De acordo com Nye (1998), em 1900 as mulheres já eram $38 \%$ da força de trabalho no mercado. Vendo que sua discriminação não diminuiu após a conquista de igualdade perante a lei, as mulheres clamavam por mais, ou seja, "elas argumentavam que a relação entre os sexos tem raízes na própria estrutura socioeconômica" (HEYWOOD, 2010, p. 35).

Friedrich Engels (1820-1895) utilizou a teoria marxista para analisar o domínio das mulheres e as constituições das famílias. Na obra "A origem da família, propriedade privada e o estado" Engels salienta que o sexismo nem sempre existiu, já que as pessoas viveram em comunidades por um tempo, e os trabalhos de homens e mulheres tinham o mesmo valor.

O socialista também indica que a origem das famílias na propriedade privada foi o que deu início à desigualdade em relação à mulher, pois "os homens assumiram também o comando da casa; a mulher foi degradada e reduzida à servidão; tornou-se a escrava da lascívia e mero instrumento para a produção de filhos" (1884 apud NYE, 1998). A partir disso, feministas iniciavam discussões sexuais, que começaram a ser desaprovadas por socialistas, sob o pretexto de que sexo era algo privado e indiscutível.

Com um marxismo cada vez menos interessado em mulheres, e mais interessado em trabalhadores do sexo masculino, feministas não achavam teorias que explicassem a discriminação sofrida pela mulher e base para as suas lutas, explana Nye (1998). Assim, concluíram que "a libertação exige que a mulher conquiste a emancipação em todas essas áreas, e não apenas que o sistema de classes capitalista seja substituído pelo capitalismo" (HEYWOOD, 2010, p. 36).

As feministas, então, viam a necessidade de contextualizar a opressão de gênero dando início ao feminismo radical, como mostra Heywood (2010). A obra "O Segundo Sexo", da filósofa francesa Simone de Beauvoir (1908-1986), utilizou teorias do existencialismo do seu companheiro Jean-Paul Sartre para analisar a desigualdade feminina. Na obra, Beauvoir (1949) afirmava que a inferioridade feminina não era natural, fisiológica ou psicológica, mas, sim, uma situação em que as mulheres eram colocadas na sociedade.

Por isso, Beauvoir defendia que a mulher devia inverter os papéis, afirmando-se contra o opressor, evitando o casamento, a maternidade e tomando o lugar dos homens no trabalho. O feminismo radical, representante da "segunda onda", foi forte entre 1960 e 1970, e buscou apoiar-se nas teorias de Beauvoir para introduzir o patriarcado como o causador da opressão feminina:

Para a maioria das feministas radicais, o patriarcado é um sistema de opressão político-cultural, cuja origem está na estrutura da vida familiar, doméstica e pessoal. A libertação feminina exige uma revolução sexual em que essas estruturas sejam abolidas e substituídas. Esse objetivo baseia-se no pressuposto de que a natureza humana é, em essência, andrógina (HEYWOOD, 2010, p. 38).

A exposição do patriarcado como o inimigo da mulher, contudo, não trouxe mudanças efetivas na sociedade, assim, havia duas possibilidades para as mulheres: declarar guerra contra os homens, ou lutar por leis que as representassem.

A reforma jurídica já tinha sido utilizada pelo 
feminismo liberal, mas dessa vez a batalha era por uma lei que considerasse o estupro um atentado violento a uma vítima, e não um furto de uma propriedade masculina. $\mathrm{O}$ resultado foi um tratamento melhor às vítimas de estupro pelos estados norte-americanos que aderiram a essa mudança na lei. Com poucos avanços, as estatísticas mostravam, mesmo assim, aumento na violência contra a mulher.

Os tipos de feminismo apresentados tiveram falhas nas teorias, mas obtiveram avanços para a mulher ao longo da história. A terceira onda do feminismo encontra-se em andamento, focando em atitudes afirmativas para as minorias, de forma que consiga sua inclusão e visibilidade na sociedade. Para Matos (2010), nesse feminismo observa-se a forte participação das brasileiras no processo de redemocratização do país, e a atenção especial para a discussão das diferenças entre as próprias mulheres (negras, brancas, indígenas...), o que pode ser nomeado como feminismo difuso.

Matos (2010, p. 68) também afirma que

Os movimentos sociais e também o feminista, defrontando-se com novas maneiras de conceber a cultura política e outras formas de se organizar coletivamente, desta vez passaram a se caracterizar por: 1) tentativas de reformas nas instituições consideradas democráticas (com a criação dos Conselhos da Condição Feminina, das Delegacias de Atendimento Especializado às Mulheres, por exemplo); 2) tentativas de reforma do Estado (com a forte participação das mulheres organizadas no processo da Assembléia Constituinte de 1988, por exemplo); 3) busca de uma reconfiguração do espaço público, por meio da forte participação de "novas" articulações dos movimentos de mulheres (mulheres negras, lésbicas, indígenas, rurais etc.); 4) uma posterior especialização e profissionalização do movimento. Este terceiro momento marca o início de uma aproximação cautelosamente construída junto ao Estado.

Nesse sentido, o que se observa concretamente é a maior e mais efetiva presença das mulheres nos espaços sociais e políticos, nos quais elas sugerem a existência e a necessidade de órgãos para que possam, efetivamente, sentirem-se agentes sociais. Deve-se também levar em conta nesse momento, as contribuições de autoras como Susan Bordo, Elizabeth Grosz, Judith Butler e Donna Haraway, que sugerem em seus estudos a ressignificação dos gêneros, discutindo o enclausuramento do conceito de gênero, a contestação da hereronormatividade, construção dos corpos, o transfeminino e a sexualidade (BITENCOURT, 2015). Observa-se, então, que o feminismo, na terceira onda, evidencia a existência de uma imensa diversidade de mulheres, de gêneros, e que, questões como raça e classe social, também influenciam em demasia as relações entre os indivíduos na sociedade.

\section{Imagem como linguagem}

Dondis (1997) explica que a linguagem humana iniciou através das imagens com pictogramas e desenhos explicativos para, posteriormente, instaurar as unidades fonéticas até chegar ao alfabeto. Portanto, a linguagem é um sistema de comunicação através das palavras, gestos e até formas de visualização.

Ao procurar o significado de uma imagem, devese ter em mente que ela foi criada para servir a algum propósito e para chegar até alguém, como afirma Dondis (1997), e, esse alguém é o espectador, aquele que utiliza sua visão para olhar a imagem. Aumont (1993) esclarece que o espectador pode assumir facetas diferentes, pois a forma como ele interpreta a imagem depende do seu estudo, sua classe social, época em que vive, sua cultura, suas crenças e seus gostos pessoais.

O tipo de imagem analisada neste trabalho não é inicialmente a imagem estática, como a da fotografia, mas, sim, uma imagem em movimento, e, mesmo considerandose tal fato, para realizar a análise, trabalha-se com o corte dessa imagem, o que a torna fixa. Deleuze (1983), por sua vez, analisou a imagem-movimento no cinema, definida por ele como a imagem que percorre o tempo de forma presente.

Inicialmente, estudiosos incluíam tudo que era imagem-movimento na tecnologia do "vídeo", definido por Machado (1995) como:

O termo vídeo abrange o conjunto de todos estes fenômenos que se estruturam através da forma simbólica da imagem codificada em linhas sucessivas de retículas luminosas. A televisão designa propriamente o modelo broadcasting de difusão de imagem eletrônica, como a simples serviço de difusão de eventos públicos ou esportivos, pronunciamentos de autoridades, teatros, musicais e concertos gravados (MACHADO, 1995, apud YOSHIURA, 2007, p. 15). 
O vídeo começou exercendo apenas uma função auxiliar, de acordo com Yoshiura (2007), pois o público tinha a possibilidade de gravar o que assistia na televisão, e com a evolução da tecnologia após a Primeira Guerra Mundial, e a procura de artistas por novas formas de expandirem seus trabalhos, tornou o vídeo uma forma lucrativa de comunicação. Isso, pois se encontra difundido com a televisão, que "tem o poder de transformar acontecimentos em espetáculos audiovisuais" (YOSHIURA, 2007, p. 20).

Não há um registro específico do surgimento do videoclipe, mas Machado (2014) afirma que os episódios musicais de "A Hard Day's Night" e "Help" da banda "The Beatles" deram início a essa mídia audiovisual, atualmente utilizada como forma de divulgação de artistas no mundo todo. No Brasil, esses vídeos começariam somente a partir de 1980, apurou Yoshiura (2007). O termo videoclipe levou tempo e foi reformulado diversas vezes:

A própria nomenclatura que define o videoclipe já nos apresenta uma característica: a idéia de velocidade, de estruturas enxutas. A princípio, o clipe foi chamado simplesmente de número musical. Depois, receberia o nome de promo, numa alusão direta à palavra "promocional". Só a partir dos anos 80 , chegaria finalmente o termo videoclipe. Clipe, que significa recorte (de jornal, revista, por exemplo), pinça ou grampo, enfoca justamente o lado comercial deste audiovisual (SOARES, 2012, p. 32).

$\mathrm{O}$ autor destaca que, além da semiótica, para analisar um videoclipe - e esta é a proposta deste estudo -, deve-se verificar a estrutura técnica desta mesma imagem, como a edição, a fusão de imagens, os enquadramentos e a iluminação.

\section{Beyoncé e "Run the World (Girls)": performance e feminismo}

Nascida em 4 de setembro de 1981 em Houston no Texas, a cantora norte-americana Beyoncé Giselle Knowles teve seu caminho artístico trilhado desde a infância, como mostra o documentário "Beyoncé: Life is But a Dream", produzido pela própria cantora. Incentivada e gerenciada pelo pai Mathew Knowles, a cantora "conquistou notoriedade e o título de artista e celebridade, ao longo dos dezoito anos da carreira musical profissional" (CATILO, 2015 apud TERRA, 2013).

Reconhecida na música, seu nome ganhou uma estrela na Calçada da Fama em Hollywood em 2006, e após várias indicações e prêmios ganhos, em 2009 Beyoncé já era considerada pela revista americana Billboard a mulher do ano. No ano de 2011, seu quarto disco, chamado "4", foi lançado e considerado o divisor de águas da carreira de Beyoncé.

No documentário "Life is But a Dream", dirigido por Beyoncé (2013), ela conta que, após anos de estresse para se manter uma artista de sucesso, precisava trabalhar sua independência artística. Por isso, decidiu demitir seu pai, que era o gerente da carreira e tomar as rédeas da situação. $\mathrm{O}$ foco deste documentário é a construção desse álbum misturando a vida pessoal da cantora, enquanto ensaiava a performance de "Run The World (Girls)", canção do clipe analisado neste trabalho.

A música, que tem como tema o poder das mulheres, é uma afirmação de independência para a cantora: "Eu estou sempre pensando em mulheres e no que precisamos ouvir. É difícil ser mulher. É muita pressão. Precisamos desse apoio e dessa libertação às vezes" (BEYONCÉ, 2013, 30min).

A relevância da cantora nos Estados Unidos, mostrada por Catilo (2015), e a percepção da própria Beyoncé em seu documentário, dão a dimensão de seu poder na música, no cinema e na mídia em geral. Sendo ela própria e o videoclipe produtos midiáticos fortes, eles são analisados a partir do uso da semiótica, objetivando identificar os significados presentes em "Run The World (Girls)", os quais evidenciem o feminismo.

Paratanto, optou-sepela análise Semiótica proposta por Martine Joly (1996), a autora defende que o trabalho da Semiótica não é desvendar qualquer significação no mundo, mas, sim, encontrar tipos de signos diferentes e identificar quais são suas significações particulares. $\mathrm{O}$ signo é definido como "uma coisa que representa uma outra coisa: seu objeto. Ele só pode funcionar como signo se carregar esse poder de representar, substituir uma outra coisa diferente dele" (SANTAELLA, 1983, p. 12).

Nessas análises, observa-se, primeiramente, a denotação de cada imagem, ou seja, seu sentido literal com descrição detalhada. Após, a análise, é evidenciada 
a conotação das imagens, desvendando sua mensagem simbólica.

Lançado dia 18 de maio de 2011 no canal "beyonce VEVO", registro da cantora no Youtube, "Run The World (Girls)" tem 4 minutos e 50 segundos de duração. Em sua narrativa, o videoclipe une dança, moda e a representação de uma revolução feminista com diferentes cenas no mesmo local: um deserto.

Figura 1 - Beyoncé empinando o cavalo preto

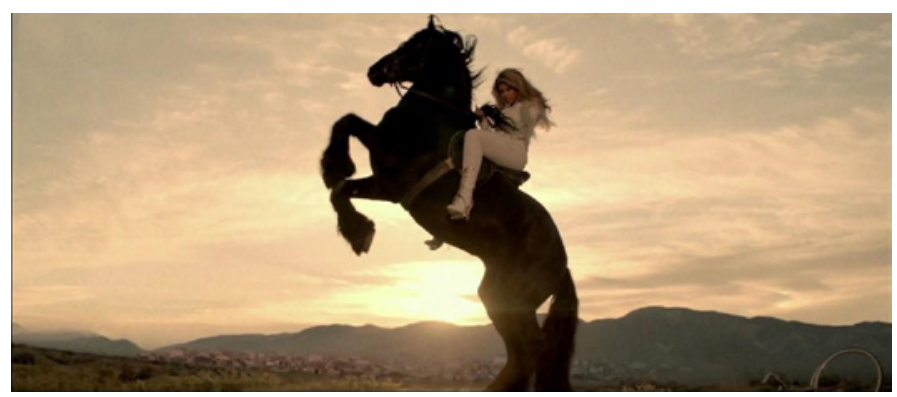

Fonte: http://beyonceonline.org/gallery

A Figura 1 mostra a cantora Beyoncé em cima de um cavalo preto empinando o animal. O local que a cena acontece é um deserto aberto, com um pouco de grama, casas e morros ao fundo. No chão há uma roda de bicicleta no canto direito. Com bastante luz clara ao fundo, a cena parece ter sido gravada no nascer do sol, ou no pôr do sol.

É importante destacar que a cantora está toda de branco: jaqueta com franjas, calça e bota de cano médio com abertura no calcanhar. E seus cabelos estão soltos e ondulados. O ângulo usado na filmagem é "contraplongée", em que a câmera fica posicionada com seu olhar de baixo para cima.

Mondro (2008) explica que este recurso causa "uma sensação de superioridade em relação ao assunto filmado". Neste caso, Beyoncé, em cima do cavalo empinado, fica engrandecida e imponente, para quem observa a imagem.

Para Chevalier (1999), o cavalo está ligado às trevas do mundo dos deuses, na psicanálise por outro lado, o animal é considerado um veículo para o humano, e, na face positiva, é visto como o representante da juventude e do desejo.

Pode-se pensar, então, que nessa figura o cavalo seja o desejo de fazer uma revolução feminista, pois os autores explicam que para budistas e filósofos quando o cavalo é guiado por um humano, ele está atrelado aos desejos deste guiador. Desde o início do vídeo,
Beyoncé se apresenta como quem guia o cavalo, o qual deve obedecer aos desejos da amazona. Pode-se pensar, também, que uma figura aparentemente frágil, a mulher, tem força suficiente para domar e conduzir um espírito selvagem, representado nesta figura como o cavalo.

O cenário que se observa é um deserto com elementos de destruição, e esse espaço pode estar ligado a histórias religiosas, sendo considerado uma extensão superficial que esconde a realidade a ser buscada. Nesse caso, a cantora estaria tirando a camada superficial em que se vive, sob leis feitas pelos homens, a fim de explanar a realidade: mulheres também são capazes de governar o mundo.

O cenário da imagem analisada confere falta de suprimentos e destruição, tal qual o apocalipse, que é definido pelo autor como "uma revelação que se apoia em realidades misteriosas" (CHEVALIER, 1999, p. 65), mas também poderia ser o fim do mundo por conta da ação humana.

Com uma narrativa em que o mundo está destruído e as mulheres tentam tomar o poder, essa destruição poderia ser entendida como a discriminação histórica contra as mulheres ou até que o modo como os homens governam o mundo e que o leva à destruição. O judaísmo, por sua vez, considera o deserto o local ideal para grandes revelações e para um povo distinguir falsos profetas de verdadeiros profetas. No clipe, quem atua como líder e profeta é a própria Beyoncé, que afirma repetidamente na letra da música que as mulheres mandam no mundo, pois são capazes de ganhar dinheiro, cuidar dos filhos e voltar ao trabalho após o parto.

Apesar do cenário de destruição na imagem, a luz ao fundo pode significar a evolução, pois a iluminação sempre aparece após tempos obscuros, e o sol pode ser considerado a esperança de mudar o cenário destruído: “as liberdades são encorajadas pela deterioração de todas as leis e de todos os esquemas arcaicos" (ELIT, 1949 apud CHEVALIER, 1999, p. 567-568).

A luz presente na figura ocorre por meio do sol, definido pelos autores como a fonte do calor e da vida, que tem raios com influências espirituais. Considerandose essas informações, pode-se pensar que a luz sugere que Beyoncé estimula ou busca uma revolução, sendo ela mesma quem coordena este movimento. Essa luz, por meio da esperança de dias melhores, revela, então, um 
novo momento para as mulheres e uma vida melhor.

Observando as vestes da cantora, elas podem ser indícios da sua personalidade, pois ela usa jaqueta, calça e botas brancas, uma cor que é descrita por Farina (2006) em dois extremos: para os ocidentais é o início de uma nova era e o bem e para os orientais é a morte e o fim de tudo.

Historicamente, Chevalier (1999) mostra que o branco é a cor do candidato, daquele que quer mudar sua condição, muito usada por políticos. Nesse vídeo, poderia Beyoncé ser considerada uma líder de uma revolução, a qual almeja por mudanças, principalmente ligadas às condições femininas.

Enfim, o branco é associado afetivamente à limpeza, à afirmação e à estabilidade que as mulheres precisam. A partir da identificação dos significados dessa cena, pode-se pensar que a cantora desejava alcançar uma meta, como mostra simbolicamente o cavalo: acabar com a destruição feita pelos homens e iniciar uma nova era, finalmente com luz e esperança para as mulheres.

Figura 2 - Beyoncé dançando

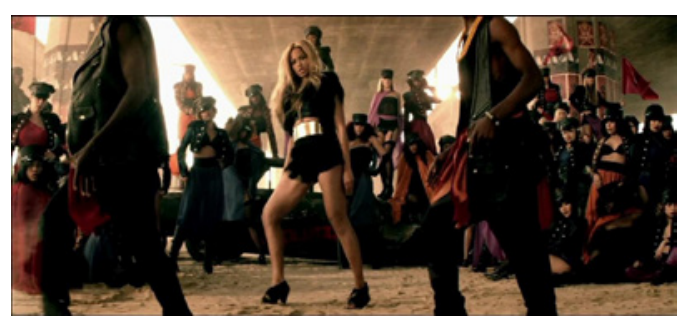

Fonte: http://beyonceonline.org/gallery

Na Figura 2, Beyoncé está usando sutiã de cone preto, colar dourado, colete preto, short preto, cinto dourado e sandália de salto preta. É interessante lembrar que esse modelo de sutiã foi usado por Madonna, na década de 1990, na turnê "Blonde Ambition", e lembrava que as mulheres também podem comandar, fazendo referência ao falo. Usando o plano conjunto, Beyoncé se encontra no centro da imagem, e na sua frente estão os dançarinos do grupo TofoTofo ${ }^{1}$ sem que apareçam seus rostos, apenas os corpos e a coreografia.

Atrás da cantora e dos dois dançarinos, há diversas mulheres que não dançam nessa cena, figurando como parte da nação feminina liderada por Beyoncé, algumas delas aparecem segurando bandeiras vermelhas com a letra "B" em preto.

1 O documentário "Beyoncé: Life is But a Dream" mostra que esses dançarinos são do grupo "TofoTofo", que ensinaram uma dança típica de Moçambique à cantora.
As vestimentas das mulheres que estão atrás da cantora, dividem-se entre a combinação de preto com outras cores: roxo, laranja, vermelho e azul escuro. Enquanto algumas estão com capas, collants, meias 7/8 e cinta liga, outras estão com calça harém ${ }^{2}$, sutiã e jaquetas cropped $^{3}$, mas todas usando quepe. Os dançarinos vestem colete, camiseta e calça preta, mas com um pano vermelho e laranja na cintura e colares amarelos.

Ao fundo da imagem há um carro com aspecto destruído e, em uma cena anterior pode-se observar a palavra "Revolution" em vermelho nesse veículo. O chão é recoberto de areia, o local é aberto, e em seus pilares encontram-se panfletos com o rosto da cantora em vermelho e branco e, também, em preto e branco. Mondro (2008) afirma que o plano conjunto serve para descrever a imagem:

Normalmente emprega-se este
enquadramento quando se deseja apresentar
o corpo inteiro de um indivíduo, ou mesmo
um pequeno grupo, revelando fisicamente
suas características físicas, bem como as
do ambiente, como por exemplo algumas
pessoas conversando animadamente em
uma sala, sendo possível ver a cada um e
aos elementos [...] do ambiente (MONDRO,
2008, p. 26)

De, de fato o enquadramento da cena premiavente descrita permite ter noção dos papéis de cada indivíduo na cena. Antes desse corte de cena, aparecem vários homens vestidos de preto, sem uniforme, e em posição de combate contra as mulheres. Beyoncé, então, se põe em frente ao seu grupo e os confronta por meio da coreografia, acompanhada dos dois dançarinos. A coreografia tem passos fortes e movimentos pesados, prezando a agilidade, o que se vê, então, é que tanto a batalha de coreografias, quanto os movimentos apresentados são características da dança hip-hop ${ }^{4}$.

Enquanto dança, nesta cena, a cantora vai até os homens provocá-los, de modo que tira pertences de seus

2 No blog da personal sytlist Roberta Carlucci, a calça harem é definida pelo modelo preso na cintura e no tornozelo, mas bem amplas nas pernas.

3 Cropped é o termo inglês para peças que parecem cortadas ao meio. No caso da jaqueta cropped sua altura termina na cintura, como afirma o site MdeMulher.

4 Hip-hop é o movimento sociocultural da cultura negra, promovendo a revolução por meio das artes como música, dança, moda e escrita, explica Costa (2005). 
bolsos, pula nas costas de um e segura o rosto de outro. No sentido conotativo, entende-se que a dança é uma linguagem que vai além das palavras, que busca "uma libertação no êxtase, quer ela se limite ao corpo, quer seja mais sublimada" (CHEVALIER, 1999, p. 319).

Beyoncé, como a líder da nação feminina, quer se libertar dos dogmas criados pelos homens do que é ser uma mulher, por isso, dança com movimentos fortes sem motivação sexual, mas, sim, com a intenção de intimidar aqueles homens com quem batalha. Pode-se entender que os dançarinos homens nas laterais da imagem são apenas figurantes da cena e não personagens da história, já que sua narrativa é feita com mulheres de um lado e de homens do outro, nunca lado a lado.

Como descrito anteriormente, as roupas das mulheres ao fundo se dividem em dois grupos: o grupo um com collants e cinta-liga e o grupo dois com calça e jaqueta militar. Um detalhe interessante é que, embora as vestes sejam diferentes, ambas as opções trabalham com a sensualidade feminina, deixando uma parte do corpo à mostra. $\mathrm{O}$ grupo um tem como foco as pernas de fora, mas na parte superior do corpo é usado um collant sem decote e uma capa por cima, enquanto o grupo dois usa calça, mas estão de sutiã por baixo da jaqueta, deixando a parte superior exposta.

A jaqueta com botões em prata, usada por um grupo de dançarinas, dá um aspecto militar para a vestimenta, além dos quepes que todas usam. Essas mulheres representam um novo exército: mantendo alguns itens tradicionais e adicionando personalidade a sua tropa.

Nas vestes, a cor preta se faz presente e, de acordo com Farina (2008), em diversas situações essa cor é associada ao temor e destruição. O vermelho também aparece nas peças de roupas, e pode remeter tanto à revolução, quanto à paixão e à agressividade de quem as utiliza. Farina (2008) também explica que o laranja, presente em detalhes das vestes, era considerado uma versão moderada do vermelho, ganhando significado próprio em culturas orientais, que o consideram a cor da transformação. O roxo, para o autor, é ligado materialmente aos sonhos das pessoas, mas afetivamente à justiça e espiritualidade, por fim, o azul escuro das vestes "indica sobriedade, sofisticação, inspiração, profundidade e está de acordo com a idéia de liberdade e de acolhimento" (FARINA, 2008, p. 102).
A combinação das cores nas vestes da nação feminina pode indicar que, através do temor (preto) as mulheres farão uma revolução agressiva (vermelho) que transformará (laranja) a sociedade em um local mais justo (roxo) e com liberdade e acolhimento (azul escuro) para elas.

Quem lidera essa revolução, novamente, é a cantora Beyoncé, que veste dourado e preto, se diferenciando das demais mulheres e em posição de destaque na figura. Sua liderança transparece através das três bandeiras seguradas pelas mulheres ao fundo.

Chevalier (1999) entende a bandeira como um símbolo de proteção, seja de uma nação, um partido ou uma pessoa. Como se pode ver que a bandeira de fundo vermelho carrega a letra " $\mathrm{B}$ " em preto, referindo-se à inicial de Beyoncé, compreende-se que ela "oferece proteção da pessoa, moral ou física, de quem ela é a insígnia".

Importante apontar, também, o local da cena, que tem uma construção com pilares e teto de concreto, aberto nas laterais e o chão coberto de areia. O pilar é a simbologia que remete ao eixo do mundo, da natureza e do ser humano, de acordo com Chevalier (1999), e também um ponto de passagem de energia.

Na mitologia irlandesa, o local que tem pilares é uma metáfora para as batalhas entre guerreiros. A areia, por sua vez, é "fácil de ser penetrada e plástica, a areia abraça as formas que a ela se moldam; sob este aspecto, é um símbolo de matriz de útero" (CHEVALIER, 1999, p. 79).

O autor ainda explica que, na psicanálise, os signos que tem relação com o útero e a maternidade, indicam a necessidade de conforto e segurança. A nação de mulheres, na narrativa do clipe, busca a segurança daquele local que é delas, porém enfrentam, nesse momento, os homens que vieram combatê-las abaixo dos pilares. Procurando o seu eixo e da sociedade feminina, Beyoncé assume o papel de enfrentamento frente a esta renovação de valores.

Figura 3 - Beyoncé e a revolução

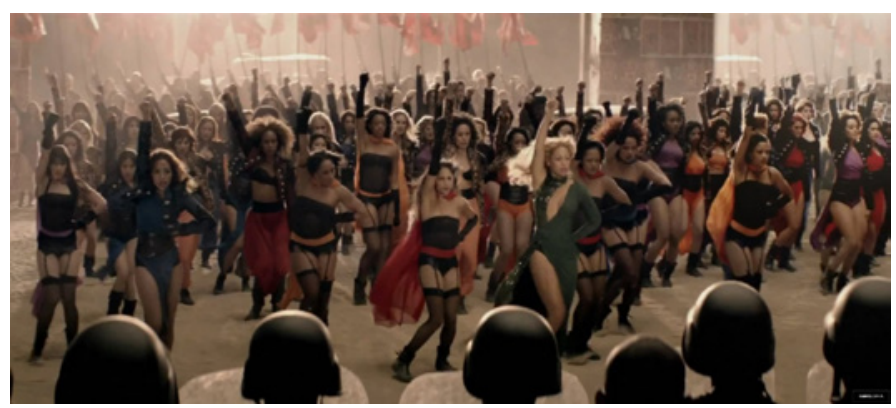

Fonte: http://beyonce.com.pl/photos/ 
A Figura 3, parte final do videoclipe, tem a cantora na frente de suas dançarinas/apoiadoras/militantes da revolução feminina, com o braço direito levantado e o braço esquerdo na cintura. As mulheres estão com as mesmas roupas da Figura 2, mas sem o quepe. Beyoncé está com um vestido verde escuro de dois tecidos diferentes: um opaco e outro com brilho, e todas as mulheres da imagem usam botas sem salto.

Ao fundo da imagem, se vê mais mulheres carregando bandeiras vermelhas com a letra "B" em preto, os pilares com panfletos da Beyoncé e os carros abandonados. Em frente às mulheres e de costas para a imagem, vê-se homens com capacete de policial e escudos, e o enquadramento é de plano geral, com o ângulo chamado plongée. O uso deste plano, de acordo com Mondro (2008), mostra todos os elementos que estão em uma cena, sem priorizar nenhum deles: "Normalmente emprega-se este tipo de enquadramento quando se deseja apresentar o ambiente no qual irá ocorrera ação" (MONDRO, 2008, p. 26).

Nesse caso, a ação da imagem é a batalha entre as mulheres e os homens, e o uso do plongée, que significa "mergulho", posicionou a câmera de cima para baixo, para dar ideia de inferioridade dos personagens, ou de que o espectador faz parte da cena, explica o autor. Este ângulo, portanto, indica que as pessoas que olham esta imagem estão participando dela também, ou seja, o espectador não é neutro no combate entre mulheres e homens.

Os homens que representam policiais, que apareceram ao longo das imagens em movimento do clipe, estão presentes na linha inferior dessa imagem e de costas para a câmera. A definição do dicionário aponta que a polícia tem a função de garantir a segurança pública e a ordem, evitando crimes e motins. Beyoncé e as mulheres sugerem querer uma mudança radical através da revolução e combate direto contra os homens. Nessa imagem, as mulheres estão armadas das suas habilidades de dança, seus corpos e sua sensualidade, enquanto os policiais estão portando capacete de proteção e escudos.

Chevalier (1999) ressalta que o capacete significa invisibilidade, invulnerabilidade e potência para quem o utiliza. O escudo é "o símbolo da arma passiva, defensiva, protetora, embora às vezes possa ser também mortal" (CHEVALIER, 1999, p. 387), ou seja, os policias nesta cena podem estar apenas tentando conter passivamente a revolução feminina, mas têm a força para atacar as mulheres a qualquer momento.

Nessa imagem, a única mulher a mudar de roupa é a líder do grupo: Beyoncé, que está de vestido verde escuro. A cor é definida por Farina (2008) como a cor da esperança, do relaxamento e do equilíbrio, que pode-se interpretar como a obtenção do equilíbrio entre mulheres e homens, desejado pela cantora. Com vestido longo, que tem recorte no busto e abertura lateral do lado direito, a cantora aposta na sensualidade para dar seu recado: "Quem somos nós e no que nós mandamos? Nós mandamos no mundo", canta enquanto coloca seu braço direito para o alto.

Chevalier (1999) destaca que o braço é o signo da força, do poder e instrumento da justiça. Historicamente, o lado direito representa o homem e o esquerdo a mulher, afirma o autor. Estariam, nessa imagem, as mulheres clamando com o braço direito para serem escutadas, como os homens já são? Já o braço esquerdo está posicionado o cotovelo na lateral e a mão na cintura, com postura confiante e assertiva. Assim, pode-se inferir que as mulheres clamam com sua razão (braço direito ao alto), sem perder sua emoção e feminilidade (braço esquerdo na cintura) nesta linguagem corporal.

A imagem final convida os espectadores a fazerem parte dessa história e da revolução que a cantora está propondo: de as mulheres enfrentarem os homens, mesmo que eles sintam que tenham que se proteger ou combatê-las.

Durante a análise de todas as imagens, Beyoncé se põe como a líder para a mudança e mostra que, se as mulheres se unirem espontaneamente a este movimento, ele ganhará forças. Com essa força, as mulheres não terão somente a esperança de dias melhores, mas estarão buscando o progresso das nações, agora e com garra. Nessa imagem final, a cantora e suas apoiadoras reforçam a exigência de justiça para as mulheres, mostrando que são uma nação fortalecida e reivindicando seu espaço.

\section{Considerações finais}

O objetivo geral deste artigo foi analisar os elementos do feminismo presentes no videoclipe "Run The World (Girls)" de Beyoncé, que foi possível após a contextualização do feminismo e das análises de imagens. A escolha deste tema foi feita de forma que reunisse um assunto de relevância social, como o feminismo, e sua relação com 
textos midiáticos como videoclipe, que estão presentes no dia a dia de jovens brasileiros e de outros países.

No texto selecionado para a análise, observa-se a cantora Beyoncé, uma celebridade e artista de grande alcance, adepta do feminismo na sua vida e na sua arte, possível de ser percebido no material para análise, o qual utiliza para a discussão os direitos das mulheres.

Neste trabalho compreende-se que determinados signos dizem muito sobre uma pessoa, uma história e o que quer ser transmitido ao público. E, o que se observa ao final deste estudo é que a cantora Beyoncé utilizou vários signos em seu videoclipe, os quais revelaram seu envolvimento com a luta das mulheres em relação à independência, à força, ao direito à sexualidade, ou seja, ao direito da mulher ser como ela quiser.

\section{Referencial}

ALVES, Branca M.; PITANGUY, Jacqueline. O que é feminismo. São Paulo: Brasiliense, 1985.

AUMONT, Jacques. A imagem. Campinas: Papirus, 1993.

BEYONCÉ, Life is But a Dream. Direção: Beyoncé Knowles \& Ed Bruke. Sony Music, Parkwood Entertainment, Columbia. Lançado em 2013. 1 DVD (89MIN), Color.

CATILO, Nathália Soares Dourado Del. Mrs. Carter Show: Um estudo de gênero sobre a produção discursiva da celebridade Beyoncé. Brasília: Universidade de Brasília, 2015.

CHEVALIER, Jean; GHEERBRANT, Alain. Dicionário de símbolos. Rio de Janeiro: José Olympio, 1999.

COSTA, Mauricio Priess da. A dança do movimento hiphop e o movimento da dança hip-hop. Curitiba: Escola de Música e Belas Artes do Paraná, 2005.

DELEUZE, Gilles. A imagem-movimento - Cinema 1. São Paulo: Brasiliense, 1983.

DONDIS, Donis A. Sintaxe da linguagem visual. São Paulo: Martins Fontes, 1997.
FARINA, Modesto; PEREZ, Clotilde; BASTOS, Dorinho. Psicodinâmica das cores em comunicação. São Paulo: Edgard Blücher, 2006.

HEYWOOD, Andrew. Ideologias politicas: do feminismo ao multiculturalismo. São Paulo: Ática, 2010.

JOLY, Martine. Introdução à análise de imagem. Lisboa, 1996.

MACHADO, Arlindo. Pré-cinemas \& pós-cinemas. Campinas: Papirus, 2014.

MATOS, Marlise. Movimento e teoria feminista:é possivel reconstruir a teoria feminista a partir do sul global? Revista de Sociologia e Política v. 18, No 36: 67-92 JUN. 2010.

MONDRO, Nielson Ribeiro. Nas entrelinhas do cinema. Joinville: Univille, 2008.

NYE, Andrea. Teoria feminista e as filosofias do homem. Rio de Janeiro: Rosa dos Tempos, 1998.

SANTAELLA, Lúcia. $O$ que é semiótica. São Paulo: Editora Brasiliense, 1983.

SARTI, Cynthia Andersen. O feminismo brasileiro desde os anos 1970: revisitando uma trajetória. São Paulo: Revista Estudos Feministas, 2004.

SOARES, Thiago. Videoclipe: o elogio da desarmonia. João Pessoa: Marca de Fantasia, 2012.

YOSHIURA, Eunice Vaz. Videoarte, videoclipe: investidas contra a "boa forma". São Paulo: Porto de Idéias, 2007.

Data de recebimento: 20/11/2017.

Data de aceitação: 20/12/2017. 